\title{
Dynamics of psychological safety in mothers raising children with special needs
}

\author{
I. Atamanova*, N. Kozlova, I. Glebova, E. Meshcheryakova, T. Levitskaya, and D. Zueva \\ National Research Tomsk State University, Tomsk, Russia
}

\begin{abstract}
There is a considerable decrease in psychological well-being among mothers raising children with special needs. Addressing the issues of providing psychological support for them is of particular importance for both researchers and practitioners. The paper presents a study aimed at exploring the dynamics of psychological safety in mothers raising children with special needs. 32 mothers whose children underwent a rehabilitation programme in a rehabilitation centre participated in the study. The key element of the psychological support programme developed for these mothers was a specific psychotherapeutic space combining hippotherapy with environmental, social and personal factors. Compared to the control group, the study participants' parameters of psychological safety showed statistically significant positive dynamics. The results obtained contribute to studying factors of psychological well-being in mothers raising children with special needs and suggest an effective way of enhancing their sense of psychological safety.
\end{abstract}

\section{Introduction}

The World Health Organization (WHO) reports that the number of featured children (those with autism, cerebral palsy, Down syndrome, cognitive impairments, etc.) is increasing every year globally [1]. The same tendency has been observed in Russia; e.g., statistics (2015) on cerebral palsy in children reported an increment in the number of new cerebral palsy cases diagnosed annually from 6854 in 2013 to 7734 in 2014 [2]. In turn, children with special needs have a transformative effect on their families as a whole and each family member, especially mothers [3-6]. Recent studies have shown that there is a considerable decrease in psychological well-being among mothers raising children with special needs [7-11]. The researchers point out that mothers of children with special needs, regardless of the nature of abnormal development, have some similar experience. They are often depressed, feeling guilty due to the birth of a disabled child and experiencing social exclusion, and their excessive involvement in raising such a child mostly leads to frustration of their basic needs. Depression, intrapersonal conflicts and neurotic reactions, distortion of parental attitudes and mother-child relationships - all these testify to a violation of adaptation to their life event connected with the birth of a child with special needs. The vast majority of these mothers are in a dire need for qualified psychological support. Therefore, addressing the issues of providing psychological support for them to

\footnotetext{
* Corresponding author: iatamanova@yandex , ru
} 
enhance their psychological well-being is of particular importance for both researchers and practitioners.

The paper presents a study aimed at exploring the dynamics of psychological safety in mothers raising children with special needs. Being a complex phenomenon, psychological safety plays a crucial role in helping people overcome difficulties in their lives and can be viewed as an indicative factor of one's psychological well-being [12-14]. According to Eksakusto and Lyz [12], Baeva [13] and others, psychological safety of a person is interpreted as an ability to keep his/her own stability in the environment with certain parameters, including stressful events and traumatic impacts, and to resist various destructive internal and external influences. This manifests itself in a feeling of inner security or insecurity in a particular situation and an ability to recognize, anticipate and overcome life difficulties. In other words, psychological safety can be regarded not only as that of being threatened under stress, but also as a personal resource enabling people to cope with stressful events.

Based on Bogomaz and co-workers' viewing of psychological safety (see, for example, [14]) and theoretical considerations by Lyz [12], it is supposed to be an integrated personal characteristic including a number of parameters. In the case of mothers bringing up children with special needs, evaluating their psychological safety requires taking into account their basic beliefs, meaningfulness in life and hardiness as well as their level of personal and situational anxiety and their emotional state.

The present study was organized as follows. Mothers whose children with special needs underwent a rehabilitation programme in a rehabilitation centre agreed to participate in a programme of psychological support. The study participants' psychological safety parameters were evaluated before and after implementing the programme to reveal their dynamics. The key element of the programme developed for such mothers was a specific psychotherapeutic space combining hippotherapy with environmental, social and personal factors. It should be noted that the idea of psychotherapeutic space is connected with Alekseičik's and Kočiūnas' views [15] on interaction between the therapist and the client in a specifically created space contributing to solving psychotherapeutic goals and objectives. A combination of such factors as being outdoors, horse riding, taking care of horses and feeding them, the participants describing their actual experience, individual and group work with riding instructors - all these were included in the programme to create this specific psychotherapeutic space.

\section{Research materials and methods}

The main objective of the study presented was to examine the dynamics of psychological safety in mothers raising children with special needs as an effect of their participation in a specifically developed programme of psychological support for them.

\subsection{Study design}

The study was designed as follows. Mothers whose children with special needs underwent a rehabilitation programme in a rehabilitation centre were invited to participate in a programme of psychological support. The study participants' psychological safety parameters were evaluated at the beginning and at the end of the programme to reveal their dynamics. The key element of the programme developed for such mothers was a specific psychotherapeutic space combining hippotherapy with environmental, social and personal factors, namely being outdoors, horse riding, taking care of horses and feeding them, as well as individual and group work with riding instructors and giving feedback about actual experience. The study conducted involved four steps: (1) psychodiagnostic I, i.e. evaluating 
the study participants' psychological safety parameters and collecting their demographic data; (2) practical, i.e. implementing the programme with one-and-a-half hour sessions once a week for three months; (3) psychodiagnostic II, i.e. re-evaluating the study participants' psychological safety parameters; (4) reflective, i.e. providing feedback by the study participants six months after their participation in the programme.

\subsection{Study sample}

32 mothers, aged from 25 to 45 , participated in the study. Middle-aged women from 30 to 40 years old comprised $75 \%$ of the study sample. Women under 30 and over 40 were presented in the sample in equal amounts of $12.5 \%$. The mean age of the study participants was 35.3.

Their children with special needs, aged from 3 to 11 , underwent a rehabilitation programme in a rehabilitation centre. The most common diagnosis in the children whose mothers took part in the study was autism spectrum disorder $(47 \%)$, the second one was cerebral palsy (28\%). Among others were the following: speech delay and mental developmental delay (10\%), motor alalia (9\%), Down syndrome (3\%) and mental retardation or intellectual disability $(3 \%)$.

The total sample was divided into two groups: experimental and control. The experimental group participated in the developed programme of psychological support for mothers raising children with special needs.

\subsection{Research methods}

The psychodiagnostic package aimed at evaluating the study participants' psychological safety parameters involved the following scales and research tools:

1) The World Assumptions Scale by Janoff-Bulman [16] modified and psychometrically checked by Padun and Kotel'nikova [17]. This scale is applied to evaluate one's basic beliefs. The modified version (in Russian) is a 37-item scale to identify one's assumptions of benevolence of the world, justice, luckiness, self-worth and controllability.

2) The Noetic Orientations Test [18] based on the Purpose-in-Life Test by Crumbaugh and Maholick [19]. This personality test (in Russian) is a self-report attitude scale to measure how purposeful and meaningful one perceives one's life to be. There are five subscales: purpose in life, process of life, result of life, locus-control (self) and locuscontrol (life).

3) Maddi's Hardiness Survey [20] translated into Russian and psychometrically checked by Leontiev and Rasskazova [21]. Hardiness is a personality construct that includes three relatively autonomous components: commitment, control, and challenge. The instrument used consists of 45 items to evaluate the three elements mentioned and hardiness in general as the sum of its components.

4) The Test Anxiety Inventory [22] modified by Hanin [23]. This 40-item tool is applied to measure both personal anxiety and situational anxiety.

\subsection{Data analysis}

The data collected were statistically treated using the SPSS Statistics package (descriptive statistics, analysis of variance and Student's paired $t$-test). 


\section{Results and discussion}

The study results indicated a low or transient level of psychological safety among the study participants before their involvement in the programme of psychological support. This was manifested in their poor mental state and reduced emotional background, a high level of anxiety and a distorted image of their future. They also lacked in self-confidence and distrusted others. It should be noted that the results obtained are in line with the literature [7-10]. Table 1 presents the study participants' initial psychological characteristics in the context of their psychological safety. It is seen that there is a number of parameters that are statistically different from the normative ones for the corresponding age group. Parameters characterising the study participants' basic beliefs (the WAS subscales) were not included in the table because there was no statistically significant difference from the normative values.

Table 1. Initial parameters of psychological safety in the total sample $(N=32)$.

\begin{tabular}{|l|c|c|c|c|c|c|}
\hline \multirow{4}{*}{ Parameters } & \multicolumn{4}{|c|}{ Descriptive statistics } & \multicolumn{2}{c|}{ ANOVA } \\
\cline { 2 - 6 } & Obtained values & \multicolumn{2}{c|}{ Normative values } & \multirow{2}{*}{$\boldsymbol{F}$} & \multirow{2}{*}{$\boldsymbol{p}$} \\
\cline { 2 - 6 } & Mean & SD & Mean & SD & & \\
\hline Maddi: Hardiness & 72.16 & 2.68 & 80.72 & 18.53 & 2.17 & 0.15 \\
\hline Maddi: Commitment & 33.03 & 1.58 & 23.23 & 4.64 & 8.19 & $\mathbf{0 . 0 1}$ \\
\hline Maddi: Control & 23.34 & 0.63 & 16.43 & 3.47 & 25.83 & $\mathbf{0 . 0 0}$ \\
\hline Maddi: Challenge & 15.41 & 0.76 & 12.43 & 2.98 & 3.28 & 0.07 \\
\hline NOT: Purpose in life & 30.22 & 1.08 & 38.91 & 3.20 & 13.84 & $\mathbf{0 . 0 0}$ \\
\hline NOT: Process of life & 23.66 & 1.07 & 35.95 & 4.06 & 27.85 & $\mathbf{0 . 0 0}$ \\
\hline NOT: Result of life & 21.50 & 0.61 & 29.83 & 3.00 & 39.42 & $\mathbf{0 . 0 0}$ \\
\hline NOT: Locus of control - Self & 19.34 & 0.92 & 24.65 & 2.39 & 7.11 & $\mathbf{0 . 0 1}$ \\
\hline NOT: Locus of control - Life & 23.41 & 1.11 & 34.59 & 4.44 & 21.75 & $\mathbf{0 . 0 0}$ \\
\hline TAI: Situational anxiety & 38.31 & 1.51 & 37.50 & 7.00 & 0.06 & 0.80 \\
\hline TAI: Personal anxiety & 47.50 & 1.18 & 37.50 & 7.00 & 15.33 & $\mathbf{0 . 0 0}$ \\
\hline
\end{tabular}

Comparison of the parameters under study in the experimental and control groups before implementing the programme of psychological support did not reveal any statistically significant difference between them.

Participating in the programme of psychological support helped mothers enhance their sense of psychological safety. Student's paired $t$-test revealed statistically significant differences in all the indicators under study in the experimental group (see Table 2). Accordingly, negative values of $t$-criterion in the table illustrate an increase in the parameter in question after participation in the programme of psychological support. Conversely, positive values of $t$-criterion indicate a decrease in the parameter of interest after participation in the programme.

In other words, participating in the programme developed helped mothers raising children with special needs become more relaxed and more determined about their time perspectives. Their level of situational and personal anxiety significantly decreased. Many of the programme participants realized their life goals more clearly, as well as their image of the future. Their level of control in turn increased, indicating that they became more confident in their ability to influence their life events and situations. Table 2 also illustrates that these mothers became less irritated by other people and the environment and more steady to negative impacts of others, thus being more aware that the world around appeared 
to be much better and they could trust others. Women who participated in the programme showed greater involvement in their life process and became more adaptive to stressful situations, overcoming some of their fears and feeling more freedom.

Table 2. Paired differences in the parameters of psychological safety in the experimental group before and after participation in the programme of psychological support $(N=16)$.

\begin{tabular}{|c|c|c|c|c|c|}
\hline \multirow[b]{2}{*}{ Parameters } & \multicolumn{3}{|c|}{ Paired differences } & \multirow[b]{2}{*}{$t$} & \multirow{2}{*}{$\begin{array}{c}p- \\
\text { value }\end{array}$} \\
\hline & Mean & SD & $\begin{array}{l}\text { Std. Error } \\
\text { Mean }\end{array}$ & & \\
\hline Maddi: Hardiness & -14.313 & 10.512 & 2.628 & -5.446 & 0.000 \\
\hline Maddi: Commitment & -9.188 & 8.199 & 2.050 & -4.482 & 0.000 \\
\hline Maddi: Control & -3.625 & 3.008 & 0.752 & -4.820 & 0.000 \\
\hline Maddi: Challenge & -1.813 & 2.762 & 0.691 & -2.625 & 0.019 \\
\hline NOT: Purpose in life & -1.625 & 3.008 & 0.752 & -2.161 & 0.047 \\
\hline NOT: Process of life & -3.750 & 3.109 & 0.777 & -4.825 & 0.000 \\
\hline NOT: Result of life & -3.313 & 2.243 & 0.561 & -5.908 & 0.000 \\
\hline NOT: Locus of control - Self & -3.188 & 2.762 & 0.691 & -4.616 & 0.000 \\
\hline NOT: Locus of control - Life & -2.750 & 3.890 & 0.973 & -2.828 & 0.013 \\
\hline TAI: Situational anxiety & 6.875 & 4.209 & 1.052 & 6.533 & 0.000 \\
\hline TAI: Personal anxiety & 3.688 & 3.198 & 0.800 & 4.612 & 0.000 \\
\hline WAS: World benevolence & -2.313 & 1.815 & 0.454 & -5.095 & 0.000 \\
\hline WAS: Justice & -1.375 & 1.025 & 0.256 & -5.367 & 0.000 \\
\hline WAS: Self worth & -1.813 & 1.328 & 0.332 & -5.461 & 0.000 \\
\hline WAS: Luckiness & -1.188 & 1.223 & 0.306 & -3.884 & 0.001 \\
\hline WAS: Controllability & -2.313 & 1.138 & 0.285 & -8.126 & 0.000 \\
\hline
\end{tabular}

Compared to the control group, the programme participants' parameters of psychological safety also showed statistically significant positive dynamics $(p<0.02)$. In addition, Student's paired $t$-test did not reveal any statistically significant differences in the parameters of psychological safety in the control group.

\section{Conclusions}

Thus, the results obtained contribute to studying factors of psychological well-being in mothers raising children with special needs and suggest an effective way of enhancing their sense of psychological safety via participating in a programme of psychological support based on a specific psychotherapeutic space combining hippotherapy with environmental, social and personal factors, namely being outdoors, horse riding, taking care of horses and feeding them, as well as individual and group work with riding instructors and giving feedback about actual experience. One of the study limitations seems to be a mixed sample in the context of diagnoses in the children with special needs whose mothers were involved in it. We realize that mothers raising children with autism, cerebral palsy or Down syndrome may differ in their psychological deficiencies and hope that our work and further research will allow us to collect more data to provide targeted psychological support. 


\section{References}

1. World Health Organization. Fact Sheets, (2016)

2. Statisticheskaya informatsiya za 2014 god [Statistical data for 2014], 5 (2015)

3. O.L. Romanova, Korsakov Journal of Neurology and Psychiatry, 9 (1988)

4. N.Ye. Karpova, T.A. Strekalova, Proceedings of the II All-Russian scientific conference «Psychological problems of a modern Russian family» (MSU, Moscow, 2005)

5. $\quad$ J.A. Resch, M.R. Benz, T.R. Elliott, Rehabilitation Psychology, 57 (2012)

6. A. Harper, T. Taylor Dyches, J. Harper, S. Olsen Roper, M. South, J. Autism Dev. Disord., 43 (2013)

7. Yu.M. Milanich, Vestnik of Pushkin Leningrad State University. Psychology, 3 (2010)

8. E.Yu. Shebanets, Bulletin of the Adyghe State University. Pedagogy and Psychology, 1 (2011)

9. E.Yu. Shebanets, T.K. Khozyainova, Bulletin of the Adyghe State University. Pedagogy and Psychology, 4 (2011)

10. E. Yu. Shebanets, F.R. Khatit, Bulletin of the Adyghe State University. Pedagogy and Psychology, 4 (2015)

11. N.V. Kozlova, D. Ye. Zueva, I.A. Glebova, Med. Psihol. Ross., 3 (2016)

12. T.V. Eksakusto, N.A. Lyz, Siberian Journal of Psychology, 37 (2010)

13. I.A. Baeva, Herzen University Journal of Humanities \& Science, 145 (2012)

14. N.V. Kozlova, S.A. Bogomaz, Proceedings of All-Russian scientific-practical conference (Southern Federal University, Taganrog, 2014)

15. A.E. Alekseičik, R. Kočiūnas, Psychotherapy by life: Intensive Therapeutic Life by Alexander Alexeichik (HEPI, Vilnius, 2008)

16. R. Janoff-Bulman, Social Cognition, 7 (1989)

17. M.A. Padun, A.V. Kotel'nikova, Psychological Journal, 4 (2008)

18. D.A. Leont'ev, Test smyslozhisnennykh orientatsiy [The Noetic Orientations Test] (Smysl, Moscow, 2000)

19. J.S. Crumbaugh, J. of Individual Psychology, 24 (1968)

20. S.R. Maddi, S.C. Kobasa, The hardy executive: Health under stress (Dow JonesIrvin, Homewood, 1984)

21. D.A. Leont'ev, E.I. Rasskazova, Test zhiznestoykosti [The hardiness test] (Smysl, Moscow, 2006)

22. C.D. Spielberger, R.L. Gorsuch, R.E. Lushene, The State-Trait Anxiety Inventory: Test manual (Consulting Psychologist Press, Palo Alto, 1970)

23. C.D. Spielberger, R. Diaz-Guerrero, Cross-cultural anxiety (Hemisphere/McGraw Hill, New York, 1983) 